\title{
A QUEST FOR EVIDENCE-BASED MANAGEMENT INTERVENTIONS/PRACTICES (EBMIS). DERIVATION AND TESTING OF MANAGEMENT INTERVENTIONS/PRACTICES IN RANDOMIZED CLINICAL TRIALS (RCTS)
}

\author{
Cosmin-Florin LEHENE ${ }^{a *}$ \\ ${ }^{a}$ Babeș-Bolyai University of Cluj-Napoca, Romania
}

DOI: $10.24818 / \mathrm{IMC} / 2020 / 01.01$

\begin{abstract}
In this paper we develop an idea regarding the introduction into the management field of a modern methodology existent already within more traditional fields such as medicine and psychiatry, or younger fields such as psychology. The idea around which gravitates all the discussion in the paper is to move towards a scientifically validated management practice. In this line of thinking, we make a quest for developing managerial interventions/practices from the existent scientifically validated theories in the field of management and previously introducing those managerial interventions/practices into organizations, test them into what is called in medicine, psychiatry or psychology a Randomized Clinical Trial (RCT). We argue that only the management interventions / practices, which have been tested in RCTs and found empirical support at a statistical significance level, constitute the Evidence-Based Management Interventions (EBMIs). We conclude presenting an example, regarding the derivation of a specific managerial intervention for the purpose of testing it in an RCT and open the discussions regarding the introduction of the managerial intervention/practice into the organizations.
\end{abstract}

KEYWORDS: research methodology, evidence-based management practice, Randomized Clinical Trial

\section{INTRODUCTION}

The classical view in the management field is that for the theory development, normally, the researchers have some ideas and suppositions - derived from the extant theory or from other sources - develop the theory, gather the data and test the theory. Then, based on the paper's findings the authors of the paper give management and practical advices to practitioners (Carlile and Christensen, 2004). This rationale is true for inductive studies (such as theory building) or for deductive ones (theory testing). The structure of the best papers in the field is designed in this modality (see Kale et al., 2002; Zimmermann et al., 2015). One can check and see the fact that the best papers in the field are generally structured in the following manner: starting with the literature review, gathering the data, analyzing the data, presenting the findings and then designing some management interventions, named in the most cases managerial/practical implications. What we do in this paper, we argue that the next step within the ontogenically development of the management field is to derive from the results obtained by the researchers some practical implications - as the things have been done until now - but previously introduced them into organizations, test that interventions/practical implications, in what in medicine, psychiatry and psychology is called a Randomized Clinical Trial (David, 2006b). Only after testing those practices in RCTs, we argue, the

\footnotetext{
* Corresponding author. E-mail address: 1ehenecosmin@ymail.com
} 
specific practice/management intervention would become an Evidence Based Management Intervention (EBMI) and it will be suitable for implementation into organizations. In this line of thinking, in this paper we make a call/quest for changing the pattern and start favorizing/prioritizing the introduction into the organizations of those management interventions with empirical support. As we are going to discuss in the next paragraphs, not any kind of empirical support will transform the specific management practice into an EBMI. For instance, the qualitative data, even if do support the management practice is not enough to make the pass from a specific managerial intervention to an EBMI. In the same line of thinking, the management interventions supported by case studies, or those conducted in an interpretative philosophical tradition, despite the fact that may found empirical support, the support is not satisfactory from a scientifically perspective, to transform those management practices into EBMIs (David, 2006b). In this rationale, we argue that a management intervention/practice in order to become an EBMI should be derived from a scientifically validated theory - theory which should have been tested for empirical support at least at the correlational level - tested in an experimental design called an RCT, and find support at a statistical significance level. Only then, we argue, the management intervention/practice will be ready for introduction into organizations. In short, what we aim for in this paper is moving towards a scientifically validated management practice. In order to better illustrate this idea of EBMIs, in the empirical part of the paper, we are going to present a very simple example using a correlational analysis. From the statistically significant correlation, we are going to develop a managerial intervention. Then, we are going to discuss how we can convert the management intervention/practice into an EBMI using an RCT. The final step is to introduce the design for what is called by psychologists, 'protocol', in order to favor the introduction of the managerial practice into organizations. Of course, the theory from which the managerial intervention/practice is derived, in most of the cases, is more complex and is substantiated by more rigorous statistical analyses than a simple correlational analysis (e.g. complex econometric models, multilinear regressions etc.). We kept the analysis simple (at the correlational level) in order to keep the focus of the readers on the main objective of our paper: deriving from a scientifically validated theory a managerial intervention/practice and test that intervention/practice in an RCT to become an EBMI.

The paper may be important for several reasons: (1) it may bring into the awareness of the research community the idea to refine some of the extant theories in the field of management depending the actual circumstances (e.g. one theory could had been found support some decades ago but now the data to not support any more the theory), (2) it may help to protect the organizations receiving pseudo-managerial interventions, (3) it may help to protect the academic management field and its ontogenetic development from the intrusion of pseudoscience, (4) it may help to protect the accredited managers and specialists and their expertise from unfair competition with different management 'specialists' without management education.

The rest of the paper is organized as follows. We begin by discussing the main contributions existent within the literature, contributions related to the topic of our paper. Then, we present the research methodology adopted for this paper. The next step is to present an empirical example in order to better illustrate the idea of EBMIs. We conclude through presenting the limitations and the conclusion derived from our paper.

\section{LITERATURE REVIEW}

Management is the administration of an organization, being a private company, NGO, political party or other type of organization. In this line of thinking, managers are the people who manage the activities conducted in the organization in order to accomplish its stated objectives (Drucker, 1954/2007). The managerial activity done in organizations by managers can be grouped grosso modo in four components/clusters: planning, organizing, leading people and controlling the activities (Daft, 2010). Along the time there have been proposed many theories, frameworks and 
models in order to assist and provide some guidance for the management practitioners. Sociology (for instance, Weber, 1864-1920), engineering (Taylor, 1856-1915) and administrative fields (Fayol, 1841-1925) have been the pioneering fields from which the researchers have been proposed some theoretical models in order to provide some guidance for the management of organizations. After the initial classical theories emerged, there have been developed various understandings of the work and activities done in organizations. These shared understandings and views of the work done in organizations can be classified such as paradigms (Bhattacherjee, 2012). For instance, human resources management paradigm, behavioral management paradigm, quantitative management paradigm, modern management paradigm (Popa et al., 2013).

In the 50's, a new pioneering approach have been introduced in the organizational and management studies, imported mainly from the military domain: strategic management. Ansoff (1918-2002), Anderson (b. 1949), Mintzberg (b. 1939) and Porter (b. 1974) have been the scholars most contributing to the introduction of the newer approach. More recently, a new approach raised in the field of management, mainly developed from the newer needs imposed by the turbulent environment: project management. All the paradigms discussed above have at their base studies elaborated using various research methodologies: case studies, correlational analyses, econometric models, qualitative analyses and so on. The idea around we develop our rationale in this paper is the fact that until now, we do not have evidence regarding how many of the findings stated in the existent management theories are evidence based (supported by data) - beyond a great bow and the gratitude which clearly deserve the founders of the management field.

This approach is called the evidence-based paradigm and is a modern approach developed in other fields. In psychology, for instance, many aspects in the dynamic-psychanalysis paradigm developed by Freud in 1920 are not anymore supported by data. According to the dynamic-psychanalysis the mental problems are due to actual conflicts - arising between the unconscious and conscious levels of the self - which are caused by past conflicts which the subject experienced in the first period of his/her life. Recently, however, the cognitive-behavioral paradigm has challenged the dynamicpsychoanalysis paradigm offering a more scientifically validated explanation. According to the cognitive-behavioral paradigm the mental problems are a result due to irrational/maladaptaptive cognitions and not necessarily due to what the subject experienced in the past (David, 2006a). In the same line of thinking, many of the aspects developed by Erikson (for instance, the Ericksonian psychotherapy), with all the respect devoted to Erickson and his work, have not been scientifically tested for empirical support using statistical tests (correlational or causality-oriented studies) (David et al, 2000). In this line of thinking, when we refer to management findings supported by data, we refer to at least hypotheses which have been tested in correlational or causality statistical studies and found statistical support, at a statistical significance level. Perhaps, this approach has not been introduced already in our field, since the management field 'feeling itself' a younger field of research, in comparison with more classical scientific fields - medicine, psychiatry or psychology for instance - until now, there is no courage to say this theory works, this theory does not work, this management practice works, this management practice does not work. More than that, the management practices derived from validated scientific theories - theories existent in the field with data support (with strongly adherence to the positivist philosophical position) are almost inexistent. At least at the authors' awareness. In this context, it is important to mention that in order a management practice/intervention to become evidence-based, two conditions must be met/complied: (1) the theory from which the practice was derived should be tested statistically and should be scientifically valid (the hypotheses within the theory should been tested in cause-effect relationships/causality or at least should be tested for a correlational relationship), (2) not only the theory should be validated by data but also the managerial practice / intervention derived from the validated theory should found empirical support in Randomized Clinical Trials - RCTs (David, 2006b). In this line of thinking, next we should define what we mean at the point we refer to an evidence-based management intervention (EBMI). Given the assumptions discussed above, an evidence-based managerial intervention is a planned intervention introduced into the organizational 
life, rigorously substantiated by a methodological and theoretical framework, implemented into one organization by a professional, with the purpose of ameliorating the organizational 'pathology' or/and in order to improve the performances and functioning of the healthy organizations. More specifically, an EBMI is applied scientific management in organizational clinical practice and/or to improve the organizations' performances in the case of healthy organizations. As we have mentioned above, the emphasis is strongly on statistics, the adherence is to a positivistic philosophical position, and particularly to a research methodology called experimental management. The equivalent of Randomized Clinical Trial/Randomized Controlled Trial in medicine, psychiatry and psychology (David, 2006b).

The idea in RCT applied to the management field is relatively simple. The organizations are randomly grouped in two or three groups. One group of firms receive some management interventions, other don't receive nothing or receive a placebo management intervention. Then, the experimenter will compare the performances of the groups. In the case the performances of the group receiving the management intervention is better than the performances of the group receiving the placebo, or in comparison with the group not receiving nothing, then the management intervention could become an EBMI. (Of course, not the organization per see receives the intervention, but the managers working in the organization.).

Regarding the statistical significance of the hypotheses emitted within the theory and practice in the evidence-based paradigm we can argue that in the medicine field, for instance, the statistical significance threshold for the empirical support for one hypothesis is 0,01 (Opariuc-Dan, 2009). It means, in order one drug to be accepted for the development and commercialization on the market the limit for errors is rigorously set. At the populational level, there cannot be more than $1 \%$ chances the drug/pill to have seriously negative consequences. The effect of the specific pill/drug must be tested several times in RCTs in order the government bodies to accredit the development of the specific drug/pill. The quest for rigor in social sciences, however, is not so high as is in the medicine. In social sciences, we can accept empirical support for one hypothesis also at the statistical significance threshold 0,05. (Opariuc-Dan, 2009). It is well-known that the correlation does not mean automatically causality (Sava, 2011). In order to make predictions is necessarily to exist a correlational relationship between the independent and dependent variables. For explanation, instead, a causality or a cause-effect relationship must exist between variables. For causality to exist three conditions must be complied: (1) a correlation between constructs must be present, (2) temporal precedence (the cause must precede the effect in time), and (3) rejection of the alternative hypotheses (through testing) (Bhattacherjee, 2012).

In this line of thinking, we argue that in the management field, for a specific theory to be accepted for derivation from it of a specific management intervention/practice the theory should be tested statistically and find empirical support at least for a correlational relationship at the statistical significance level 0,05 . In the same line of thinking, a managerial intervention to be classified such as an EBMI, the intervention/practice should be tested in an RCT and find empirical support at the same 0,05 statistical significance level.

The management practices/interventions derived from a scientifically validated theory, which can be tested and then implemented into the organizations, could be grouped according the main fields of management: strategic management EBMIs, operations management EBMIs, human resources EBMIs, small and medium enterprises EBMIs and so on. On the other hand, the organizations should be open to implement 'only' those management interventions supported by data. Recently, have been published some studies in the strategic management field which examine the existent alliance management practices within various firms and the relationship of those alliance management practices with firm's performance (Sluyts et al., 2011). In these studies, the authors drew upon interviews, designed the existent alliance management practices and through a questionnaire tested the relationship between the implementation of those alliance management practices and firm's performance. Despite the fact that, as mentioned above, the theory is assimilated such as scientifically validated, the alliance management practices should be tested for 
causality in RCTs to check if the firms implementing those alliance management practices obtain better performances in comparison with the firms not implementing the alliance management practices. But for a such approach to be possible it is necessarily therefore a strong adherence to positivism research and to a positivist philosophical position. But what we mean by a positivist philosophical position? There are three classical philosophical orientations developed along the time in social science research: positivism, critical realism and interpretive/constructionism (Piekkari et al., 2009; Welch et al., 2011; Welch and Piekkari, 2017). Firstly developed, the classical positivism focuses on quantitative data analysis, searches for objectivity and causality and for hypotheses which are generalizable among various settings (Chelcea, 2007; Welch et al., 2011). The positivist - oriented philosophical position, promoted initially by Comte (1798-1857), searches for explanations of a social phenomenon based on the following core axioms: there is a single reality which can be discovered, controlled and predicted; observations are possible to be realized without the personal involvement; generally, the personal involvement in research is view as a source of bias; the results could be obtained time and context-free (Welch et al., 2011; Welch \& Piekkari, 2017). In general, the positivists argue that there is possible to identify the cause of a specific social phenomena and then generalize that finding to other contexts. Given these assumptions, the focus of the research conducted in this tradition is on statistical measurement and testing, through applying various statistical techniques - such as regression, correlation, difference tests, factorial analysis - the focus being on variables and investigations conducted for explanation. The second paradigm, called the interpretive, searches for the development of new theories or theoretical explanations based on other set of core axioms: the reality is socially constructed; the observations are value laden and cannot be separated or independent by researcher's value; the researcher is an actor of the social world and his beliefs and values influence the outcome and the interpretation of the world; causes and effects shape each other and is not possible to precisely separated them (Chelcea, 2007; Welch et al., 2011; Welch and Piekkari, 2017). In this line of thinking, the scientific research conducted in the interpretive tradition focuses on the context as a whole, and on the subjective experience of the actors involved. The preferred research designs of the scientific theories built on this tradition are the case studies, through applying scientific methods such as qualitative analysis through procedures such as interviews and text analyses. The third philosophical position discussed in this paper is the most recently developed called critical realism. Critical realism philosophical position was promoted recently by Baskar (1944-2014) and Ragin (b. 1952). The critical realism researchers take a medium position between the paradigms mentioned above (Wynn and Williams, 2012). At their turn, critical realists develop their ideas based on a different set of core axioms. According to critical realists: the truth is out there but we are not able to fully reach it; the observations in order to produce valid explanations is necessarily to take into account both the causality and the context; the focus is on case studies as a whole - these studies are called contextualized explanations (Welch et al., 2017). The critical realists align their view with the positivists at the ontological level (there is a single truth, value free depending the researcher) and with the interpretivist at the epistemological level - but our understanding of the truth is limited (Wynn \& Williams, 2012). The preferred method in this tradition is the single case study (Ragin, 1997). These three orientations - depending their philosophical stance - are the main philosophical positions a research could be conducted in social sciences. The philosophical positions we have discussed above are developed around a set of criteria generally accepted among the research community members: ontology and epistemology. Within various fields, in the scientific literature, there are also other approaches in order to classify the philosophy of science debates. For instance, in psychology, David (2006b) discusses about three paradigms in sciences within which all the epistemological debates could be classified: positivism, phenomenology and hermeneutics/interpretivism. Bhattacherjee (2012) in Social Science Research discusses about the history of the scientific thought presenting the manner the scientific knowledge was built along the time. His classification of social science paradigms is built on Burrell and Morgan's (1979) work and is focused on objectivity and the social change process. The classification comprises the 
Radical Structuralism, Radical Humanism, Functionalism and Interpretivism. The emphasis in this paper is on the positivistic philosophical position. Recently, have been appeared numerous critiques, well-grounded, ontologically and epistemologically correct, regarding the research conducted in the positivistic orientation. Some critiques come from the interpretive tradition (Platt, 1992; Stake,1995) and others from critical realism tradition (Ragin, 1997). Both types of positivism research have been criticized recently: qualitative (see Dyer and Wilkins, 1991) and quantitative positivism (see Ragin, 1997). This debate is not new per see, however. Weber (1864-1920), Simmel (1858-1918), Husserl (1859-1938) pioneered the research conducted in the antipositivism tradition in the various decades in the past century (Chelcea, 2007). What we argue in this paper, is that even if the interpretive or critical realism assumptions are correct - it means, at the ontological level in social sciences the reality and the truth cannot be fully understood and there is no one single truth an emphasis only on interpretive or critical realism research will not advance the society. As a result, we will get stuck in this stage of development along our social ontogenesis (Bhattacherjee, 2012). The position we adopt in this paper, is that the critique by interpretive or critical realism researchers regarding the fact that the positivists employ the same rationale as their colleagues in the natural sciences is correct, but in order to advance the society is necessary to employ a positivistic orientation. Conducting social research only in interpretive or critical realism traditions we will get stuck in the present and we will not take advantage, for instance, by modern statistical analyses and methods developed in the last 50 years.

In this rationale, what we specifically do in this paper is to make a call for the development of management interventions/practices supported by empirical data, with strongly adherence to positivism. Based on the positivistic philosophical position, as discussed above, we think what is needed now in the field of management is the development of management interventions/practices with empirical support named here EBMIs. We argue that currently we have enough scientific theories and the management field has accumulated enough data in order some management theories without empirical support to be refined, abandoned those in which the data do not support the proposed theory, or put in the management history books those theories within which in the past the data supported the theory but now the data do not support any more the theory. In the same line of thinking, only the management interventions / practices which find empirical support according the methodology described in this paper should be introduced into the organizations. The rest of them should be abandoned or put in the management history books if the case. Contrary, in the case the management interventions / practices without empirical support, or those for which the data invalidated the intervention, are introduced into organizations, those management interventions/practices would become pseudo-managerial interventions and perhaps will do more harm than good for the specific organization. The approach described above is the same with that developed among many decades in medicine (Evidence Based Medicine) or psychology (Evidence Based Psychology) (David, 2006a). In this line of thinking, nobody could imagine that a physician will give a patient a pill/drug previously the medicament to has been rigorously tested for empirical support in an RCT. Or, a psychotherapist will give a specific psychological therapy to a patient previously the therapy has been scientifically tested for clinical effect in an RCT. The same approach could be implemented also in the organizational and management filed. In order to promote the management of sustainable organizations the managers should have access to a list/set of evidence-based management interventions/practices (EBMIs) and to the prescription regarding how to implement those interventions/practices into organizations.

From the administrative side, these interventions/practices could be promoted in various countries as our colleagues in psychology do in Romania. In Romania, for instance, there is a government accredited institution called The Collegium of Romanian Psychologists (CRP) with various roles regarding the practice of psychology: (1) accreditation of the validated psychological therapies/psychotherapies, (2) monitorization of the implementation of the accredited psychological therapies / psychotherapies, (3) accreditation of the Romanian psychologists. Overall, the CRP monitors the practice of psychology in Romania. Within the board in the CRP there are included the 
most influential academic psychologists from various Romanian universities (David, 2006a). The same approach could be implemented in the management field. Eventually, the Romanian Management Academic Society could take this role similarly to our colleagues in psychology. The idea is that in Romania, or elsewhere, in order to manage sustainable organizations, there should exist an accredited institution to monitor and accredit the empirically validated management interventions/practices (EBMIs) and abandon those without data support. In the same time, the accredited institution should monitor the implementation in practice of the EBMIs and the formation of the new generations of managers, if possible, according to a management educational ideal (Lehene, 2019). Given the assumptions mentioned above, next we are going to illustrate an example of a scientifically validated theory and a practice derived from the theory, which can be assimilated to an EBMI after testing it in an RCT. The context from which the example is extracted is a study in the field of strategic alliances and partnerships conducted in medium and large companies in Romania.

\section{RESEARCH METHODOLOGY}

This paper is designed to be a theoretical paper, enriched with an empirical example, elaborated in order to introduce a new methodology regarding the practice of management. As the teachers in the high-schools or in the universities use didactic methods such as the problematization, didactic dialogue or the heuristic conversation (Albulescu \& Albulescu, 1999) in order to start the discussions, we argue that in research we can implement also the same approach. We can present the theoretical framework, or the idea we want to develop, then we can give an example from practice in order to better introduce the framework and opening the discussions in the field.

From another angle, the approach is similar with using case studies in order to build, test or refine one theory. Some recent studies have showed the modalities we can test or refine a theory with other methods. For instance, case studies. Gilbert (2005) used eight cases in order to test and refine the theory of organizational inertia. Szulanski and Jensen $(2006,2011)$ used one case - the proverbial $\mathrm{N}=1$ - in order to test the theory of knowledge transfer in the multinational contexts.

In this line of thinking, in order to better illustrate the idea of EBMIs (e.g. what are the EBMIs, when does a managerial intervention becomes evidence-based) we use data from a recently closed project in order to better illustrate the idea we want to develop. The data was collected from the field of strategic alliances and partnership between organizations. We used a questionnaire implemented at the national level in order to capture the innovative and productivity-oriented performances of 46 best performers medium and large companies in Romania.

There are some advantages and disadvantages in working with secondary data. Secondary data are data collected by the researcher in other projects with different purposes from the current project the researcher is working on (Chelcea, 2007). Regarding the main advantages, the cost and time of collecting the data will be lower in comparison with starting a new process in data collection. Second, the researcher will be more familiarized with the field of research and other related fields at the point he/she had previously collected and already analyzed the existent data. Additionally, he/she can better track the evolution of a social phenomenon in time at the point the data was collected with some periodicity, at some specific intervals in time.

Regarding the main disadvantages of using secondary data is the fact that the questions raised by the investigator could have different responses depending the initial purpose of the study. According to Chelcea (2007) the purpose of the study may seriously impact the answers provided by the respondents. Using secondary data, we cannot omit the probability that the data collected in the initial study to have been collected in inappropriate emotional contexts, which again, can seriously impact the answers provided by respondents. In general, the disadvantages of secondary data increase at the point the researcher is not familiarized with the context the initial study was conducted. For instance, there can exist errors regarding the fidelity or validity of the initial study. 
In our study, the researcher is completely familiarized with all the aspects mentioned above and has looked and monitor for the elimination of the possible errors.

The work modality will be displayed next. First, we are going to present the findings (the hypotheses supported by data). Then, from the hypotheses supported by data we are going to develop some alliance management practices and discuss how they can be tested in experimental designs in order to become EBMIs. As discussed above, in order a managerial intervention/practice to become evidence-based both the theory from which the practice was derived and the practice should find empirical support at the statistical significance level.

\section{THE DEVELOPMENT OF AN EBMI. EXAMPLE}

\section{Step 1. Testing the theory}

In order to present our ideas, we are going to present a very simple example. In 2017, we have asked 46 managers (20 CEOs, 10 other top executives, 10 middle managers, five operations managers, one marketing specialist) of 46 of the best performers medium and large companies in Romania regarding the presence of some alliance management practices in their company in a larger project. We wanted to know if the companies utilize this kind of practices and the relationship between those alliance management practices with firm's productivity and innovative performances. From the project's data base, we have selected some relevant items for this paper for the analysis and discussion in the context of our framework. In the Table 1 one can check the results of our investigation.

Table 1. Descriptive statistics and correlation matrix

\begin{tabular}{|c|c|c|c|c|c|c|c|c|c|c|c|c|}
\hline & Mean & S.D. & FormProced & PowRelg & AllExpShare & $\begin{array}{l}\text { All } \\
\text { DB }\end{array}$ & AllAcces & Turnover & CompPosi & CustoSatisf & NPD & $\begin{array}{l}\text { Imprv } \\
\text { Prod }\end{array}$ \\
\hline FormProced & 3.98 & .830 & 1.00 & $.326^{*}$ & $.421 * *$ & $.391 * *$ & $.372 * *$ & $.360 * *$ & $.517 * *$ & $.531 * *$ & .098 & .223 \\
\hline PowRelg & 3.54 & 1.277 & & 1.00 & $.777 * *$ & $.540 * *$ & $.754 * *$ & $.274^{*}$ & .206 & .189 & $.263^{*}$ & .184 \\
\hline AllExpShare & 3.11 & 1.215 & & & 1.00 & $.533 * *$ & $.616^{* *}$ & $.352 * *$ & .244 & $.261 *$ & .207 & .168 \\
\hline All DB & 3.59 & 1.203 & & & & 1.00 & $.607 * *$ & $.282^{*}$ & $.375 * *$ & $.333 *$ & .177 & .190 \\
\hline All Acces & 3.46 & 1.328 & & & & & 1.00 & .239 & .196 & .086 & $.319 *$ & .172 \\
\hline Turnover & 4.20 & .833 & & & & & & 1.00 & $.420 * *$ & $.533 * *$ & $.677 * *$ & $.446^{* * *}$ \\
\hline CompPos & 4.22 & .892 & & & & & & & 1.00 & $.740 * *$ & $.406^{* * *}$ & $.277^{*}$ \\
\hline CustoSatisf & 4.09 & .812 & & & & & & & & 1.00 & $.459 * *$ & $.455^{* *}$ \\
\hline NPD & 4.09 & 1.112 & & & & & & & & & 1.00 & $.568 * *$ \\
\hline ImprvdProd & 4.17 & 1.102 & & & & & & & & & & 1.00 \\
\hline
\end{tabular}

FormProced = formal and clear procedures regarding the formation and management of firm's strategic collaborations

PowRelg = if the case, the relegation of power to the alliance managers

AllExpShare = alliance experience sharing within the company

All DB $\quad=$ the extent within the company exists an alliances monitorization data base

All Acces = alliance managers access to the knowledge from prior and ongoing firm's strategic collaborations

Turnover = the growth of company's turnover due to its strategic collaborations

CompPos = the improved competitive positioning of the company due to its strategic collaborations

CustoSatisf = an increased in customers satisfaction due to company's strategic collaborations

NPD = new product development due to company's strategic collaborations

ImprvdProd = improvement of company's existent products due to company's strategic collaborations

$* * p$-value $<0.01, * p$-value $<0.05$

Source: author's own elaboration based on the managers' answers

One can check in the table above, that not all the alliance management practices have an impact in increasing the firm's performance due to its strategic collaborations. For instance, according to our data, the design and utilization of formal and clear procedures for the formation and management of firm's strategic collaborations represent an indication of firm's improvement of productivity related performances (e.g. turnover increase, better competitive positioning, more satisfied customers) but not also regarding its innovative performances (e.g. new product development, incremental improvement of the existent products). (Performances as measured in this paper.) It means, according to our data, the companies obtaining better productivity related performances in comparison with those companies obtaining poorer productivity related performances use, at a greater level, formal and clear procedures in the process of formation and management of their 
strategic collaborations. We can theorize now, based on the results obtained and in the base of other existent studies in the field (Bouncken et al., 2016; Hoetker \& Mellewigt, 2009; Krishnan et al., 2015; Nielsen \& Gudergan, 2012): the adoption of formal and clear procedures by the medium and large firms at the point they enter into one collaboration is an indication of increasing their productivity related performances, but not also regarding their innovation related performances.

In the same line of thinking, we can observe that between the extent the company has put in place a data base containing information regarding its past and present alliances and company's improvement of productivity related performances, but not also the innovation related performances, is a direct, positive and statistically significant relationship. Again, based on our findings and other researchers (Sluyts et al., 2011) we can theorize that the medium and large companies in order to increase their productivity related performances should develop a data base in order to monitor their strategic collaborations. The development of a data base in order to monitor firm's past and current alliances is not an indication of increasing firm's innovative related performances.

Based on the findings mentioned above - as is the classical view in the management field - we can give management advices and elaborate practical implications for practitioners. However, what we argue in this paper is that there is needed an additional step to be introduced in the management field: derive a managerial intervention/practice from the findings and test that managerial intervention/practice in an RCT, previously to introduce that intervention into practice. That managerial intervention/practice tested in an RCT will become an EBMI.

\section{Step 2. Derive a management intervention / practice from the theory and test the management intervention / practice in an RCT}

We have seen that there is a positive relationship between some specific alliance management practices and the productivity related performances. (From our study as well as from other researchers.) However, just because the theory found empirical support and it was replicated and were obtained the same results in other studies, does not mean automatically that also the alliance management practices are scientifically validated (David, 2006b). In order a specific alliance management practice to be assimilated such as an EBMI it should be tested in an RCT and find support at least at the 0,05 - significance level. Only after being tested in an RCT the specific alliance management practice can be assimilated such as EBMI and should be implemented into organizations. Given our example, as long as the companies obtaining better productivity related performances (e.g. turnover increase, better competitive positioning, more satisfied customers) use formal procedures in the process of forming new alliances and managing their strategic collaborations, we could now develop some specific interventions to be introduced into the organizations for experimental purposes. For instance: Partner Screening Form, Cultural Fit Evaluation Form, Needs v/s Wants Checklist, Alliance Metrics Framework (Kale et al., 2002). All these specific interventions are going to be introduced into one group of firms, grouped in one single pack, constituting the 'managerial therapy'. Next, we could randomly select two or three groups of similar characteristics firms (using criteria such as size, country etc.). One group of firms receive the pack of interventions mentioned above, other group does not receive nothing, or receives a less intensive intervention/less interventions. Next, we need to measure the performances of the firms in each group at $\left(t_{0}\right)$. After the specific period of time, at the $\left(t_{1}\right)$, we compare the groups of firms in terms of the existent differences, regarding their performances. If the managerial interventions presented above are EBMIs then the performances of the group receiving them are superior, at the statistical significance level, in comparison with the group not receiving nothing, or the group receiving a less intensive managerial intervention/less managerial interventions.

There are some paths suitable for experimental designs. We are not going to insist on the topic since probably all the readers are aware of those paths. More than that, they are included in most of the methodology of quantitative research books. We are going to name here the Paired Samples T Test, ANOVA and ANCOVA techniques, Explicative Regression Analysis (Sava, 2011). 


\section{Step 3. Give practical advices regarding the introduction of the EBMI into organizations and monitor the introduction and evolution of the organization in time}

The next step is very important, and in many cases, it may be neglected by 'management therapists'. After the managerial intervention, very important, derived from a scientifically validated theory, was tested in an RCT and found empirical support, it can be introduced into organizations such as an EBMI. However, previously the 'management therapist' start introducing a specific EBMI into an organization he/she needs to complete an entire pre-therapeutic process: (1) clinical evaluation - previously introducing an EBMI you should know which is the problem of the organization, (2) case conceptualization - the second step is that once you know which is the problem the organization faces, now you need to know which is the cause of the problem, (3) introducing the EMBI to solve that problem and (4) developing an adequate therapeutic relationship with the managers in order to facilitate the implementation of the EBMI and the monitorization of the evolution of the organization in time (David, 2006a). This procedure is called Managerial Therapy, it comprises complex steps to follow and will the subject of the discussion in a next paper.

\section{LIMITATIONS}

There are also some limits regarding our paper. Some limits arise from the paper itself and some limits arise from the idea developed in the paper. First, regarding our paper, the main limit is that we have not an empirical example regarding testing the specific alliance management practice in an RCT in Romania. Would have been interesting to have the possibility to present also an empirical example regarding the process of testing the practice into an RCT and introduction of the practice into one organization. However, perhaps, this limit could suggest the novelty of the idea itself. Second, regarding the idea developed in the paper, is challenging to introduce a validated methodology from other fields into another field. Perhaps, for instance, the organizations, as 'patients', will not be open to test the management practices on themselves. It will be very challenging to convince the organizations to implement for experimental purposes the specific management interventions.

\section{CONCLUSIONS}

In this paper we have intended to develop an idea regarding moving towards a scientifically validated management practice. This idea represents a powerful movement happening at the international level in other fields (e.g. medicine, psychiatry, psychology) and perhaps is the direction we in the management field we need to move also. The idea around we develop our paper is that a managerial practice/intervention previously been introduced into organizations should be tested in an RCT for empirical support. It is important that not only the theory from which the theory was derived to be scientifically valid - as is the current view in the management field - but also the practice itself to find empirical support in an RCT. In this rationale, we argue, that only those management practices who have passed the experimental test and found support should be named EBMIs and be introduced into organizations.

\section{REFERENCES}

Albulescu, I. \& Albulescu, M. (1999). Didactica disciplinelor socio-umane. Cluj-Napoca: Napoca Star.

Bhattacherjee, A. (2012). Social Science Research: Principles, Methods and Practices. Florida: Textbooks Collection.

Bouncken, R., Clauß,T. \& Fredrich, V. (2016). Product innovation through coopetition in alliances: Singular or plural governance? Industrial Marketing Management, 53, 77-90. 
Burrell, G. \& Morgan, G. (1979). Sociological paradigms and organizational analysis: elements of the sociology of the corporate life. Burlington: Heinemann Educational Books.

Carlile, P.R. \& Christensen, C.M. (2004). The cycles of theory building in management research. Harvard Business School Working Paper. Version 5.

Chelcea, S. (2007). Metodologia cercetării sociologice. Metode cantitative și calitative. București: Editura Economică.

Daft, R. (2010). Understanding the theory and design of organizations. Mason, OH: South-Western Cengage Learning.

David, D., Băban, A., Holdevici, I. \& Szamoskozi, Ș. (2000). Intervenție cognitiv-comportamentală in tulburările psihice, psihosomatice și optimizare umană. Ediția a II-a. Cluj-Napoca: Risoprint.

David, D. (2006a). Psihologie clinică și psihoterapie: fundamente. Iași: Editura Polirom.

David, D. (2006b). Metodologia cercetării clinice: fundamente. Iași: Editura Polirom.

Drucker, P (1954/2007). The practice of Management. Classic Drucker Collection. UK: Elsevier.

Dyer, W. G. \& Wilkins, A. L. (1991). Better stories, not better constructs, to generate better theory: A rejoinder to Eisenhardt. Academy of Management Review, 16(3), 613-619.

Gilbert, C.G. (2005). Unbundling the Structure of Inertia: Resource Versus Routine Rigidity. Academy of Management Journal, 48(5), 741-763.

Heimeriks, K., Klijn, E. \& Reuer, J. (2009). Building Capabilities for Alliance Portfolios. Long Range Planning, 42, 96-114.

Hoetker, G. \& Mellewigt, T. (2009). Choice and performance of governance mechanisms: matching alliance governance to asset type. Strategic Management Journal, 30, 1025-1044.

Kale, P., Dyer, J. \& Singh, H. (2002). Alliance capability, stock market response, and long-term alliance success: the role of the alliance function. Strategic Management Journal, 23, 747-767.

Krishnan, R., Geyskens, I. \& Steenkamp, J-B. (2015). The effectiveness of contractual and trustbased governance in strategic alliances under behavioral and environmental uncertainty. Strategic Management Journal, 37(12), 2521-2542.

Lehene, C. (2019). Adaptation of an educational ideal and refinement of the didactic strategies used in the management pedagogy in Romania. Educatia 21 Journal, 17, 151-163.

Nielsen, BB. \& Gudergan, S. (2012). Exploration and exploitation fit and performance in international strategic alliances. International Business Review, 21, 558-574.

Opariuc-Dan, C. (2009). Statistică aplicată în științele socio-umane. Noțiuni de bază - Statistici univariate. Cluj-Napoca: Editura ASCR.

Piekkari, R., Welch, C. \& Paavilainen, E. (2009). The Case Study as Disciplinary Convention: Evidence from International Business. Organizational Research Methods, 12(3), 567-589.

Platt, J. (1992). „Case Study” in American Methodological Thought'. Current Sociology, 40(1), 1448.

Popa, M., Lungescu, D. \& Salanță, I. (2013). Management: Concepte, Tehnici, Abilități. ClujNapoca: Editura Presa Universitară Clujeană.

Ragin, C. (1997). Turning the Tables: How Case-Oriented Research Challenges Variable-Oriented Research. Comparative Social Research, 16, 27-42.

Sava, F. (2011). Analiza datelor în cercetarea psihologică. Cluj-Napoca: Editura ASCR.

Sluyts, K., Matthyssens, P., Martens, R. \& Streukens, S. (2011). Building capabilities to manage strategic alliances. Industrial Marketing Management, 40, 875-886.

Stake, R. E. (1995). The art of case study research. Thousand Oaks, CA: Sage.

Szulanski, G. \& R.J. Jensen (2006). Presumptive Adaptation and the Effectiveness of Knowledge Transfer. Strategic Management Journal, 27, 937-957.

Szulanski, G. \& R.J. Jensen (2011). Sumantra's Challenge: Publish a Theory-testing Case Study in a Top JournaL, in R. Marschan and C. Welch (eds). Rethinking the Case Study in International Business and Management Research, Cheltenham: Edward Elgar, 107-123. 
Welch, C., Piekkari, R., Plakoyiannaki, E. \& Paavilainen-Mantymaki, E. (2011). Theorising from case studies: Towards a Pluralist Future for International Business Research. Journal of International Business Studies, 42, 740-762.

Welch, C. \& Piekkari, R. (2017). How Should We (Not) Judge the 'Quality' of Qualitative Research? A Re-assessment of Current Evaluative Criteria in International Business. Journal of World Business, 52(4), 714-725.

Wynn, D. \& Williams, C.K. (2012). Principles for conducting critical realist case study research in information systems. MIS Quarterly, 36(3), 787-810.

Zimmermann, A., Raisch, S. \& Birkinshaw, J. (2015). How Is Ambidexterity Initiated? The Emergent Charter Definition Process. Organization Science, 26(4), 1119-1139. 